\title{
Analyzing Sociocultural Constructivist Interactions of Students during Geographical and Environmental Research Project in the social Web 2.0. A Case Study of Greek High School Students
}

\author{
Evi Exarchou ${ }^{1}$, Aikaterini Klonari ${ }^{2}$ \\ ${ }^{\text {(}(P h D ~ C a n d i d a t e, ~ D e p a r t m e n t ~ o f ~ G e o g r a p h y, ~ U n i v e r s i t y ~ o f ~ t h e ~ A e g e a n, ~ G r e e c e) ~}$ \\ ${ }^{2}$ (Assistant professor, Department of Geography, University of the Aegean, Greece)
}

\begin{abstract}
Today, there are many tools in the social Web 2.0 that created specifically for the educational audience, proposed in the learning process and used with great interest of both students and teachers at all levels of education. The offered possibilities of these tools encourage the research initiative, the configuration of new ways of communication, collaboration, interaction and reflection, and also the common contribution of knowledge building process. In this study considers the following research question: Does the sociocultural constructivist interaction of students in the social Web 2.0 affect their cognitive development and their geographical and environmental approach to the research issue? Data for this paper were derived from a small sample of Greek high school students $(N=16)$ who participated in an eight-month educational research project, using the new applications and extensions of the social Web 2.0. The research question was answered through quantitative content analysis (QCA) and social network analysis (SNA). We found that the sample created an active social network (with remarkable distinction in the cohesion, power and role structures) and reached the higher phase of sociocultural constructivist interaction, progressively developing essential skills for an organized and integrated geographical and environmental approach to the research issue.
\end{abstract}

Keywords: Content Analysis, Geographical and Environmental Research, Social Network Analysis, Social Web 2.0, Sociocultural Constructivist Interaction

\section{INTRODUCTION}

The last twenty years the web has grown rapidly and today its application areas are limited only by the imagination. Also, the extent use and the number of information systems show the dynamic and evolution, which are continually expanding with new ideas and technologies, with significantly the Semantic Web and Web 2.0 (or social computing). Now, the web role expands and primarily affects the functioning of business, economy, industry, banking, education, government, media, and the daily way of life, work and entertainment of the majority of people. Thus, the Information Technology and Communications acquire new dimensions as Technology Innovation and Transformation, giving the user an active and dominant role $[1,2,3,4]$.

In the recent educational research literature $[5,6,7,8,9,10,11,12,13,14,15,16]$, there has been considerable interest in the possibilities of social computing for education. There are variety of tools in the social web era that created specifically for an educational audience, proposed in the learning process and used with great interest of both students and teachers at all levels of education. Some of these tools are the following: podcasts (e.g., iTunes), blogs (e.g., Blogger, Wordpress), wikis (e.g., PBWiki, Wikispaces), social bookmarking tools (e.g., del.icio.us, Diigo), social networking tools (e.g., EduSpace, Facebook, Ning), social media sharing tools (e.g., Flickr, SlideShare, YouTube), collaborative writing tools (e.g., Google docs, Zoho), virtual 3D community platform (e.g., Second Life), and social library tools (e.g., LibraryThing). Redecker et al. [17] note that "although the social computing originated outside educational institutions, it has huge potential in formal Education and Training (E\&T) for enhancing learning processes and outcomes and supporting the modernisation of European Education and Training (E\&T) institutions", promoting the opening of the school in society, through multilateral, cooperative and flexible curricular activities.

Those involved in the online learning process, have a growing awareness of the benefits of constructivist online learning environments that enable students to reflect upon their learning and to understand their own learning processes, note Parker and Chao [18]. Also, Woo and Reeves [19] support that by using web applications and extensions, students can develop new forms of interaction between them. In particular, the above authors note that "interaction is an essential ingredient in any learning process. However, every interaction does not lead to increased learning. When interaction has a direct influence on learners' intellectual growth, we can say the interaction is meaningful. The precise meaning of meaningful interaction is strongly related to the learning theories underlying the development of particular learning environments". According to Kanuka and Anderson [20] the web tools provide "an interactive environment that supports implementing 
constructivist strategies...Constructivist learning theories are becoming widely accepted in all fields of education, including the application of technology to teaching and learning...Knowledge is generated through social intercourse, and through this interaction we gradually accumulate advances in our levels of knowing". Also, the Stauffacher et al. [21] paper supports that knowledge is constructed and acquired within experiential activities in the political, cultural and social environment "theory of socialcultural constructivism". Based on the constructivist view of learning, new knowledge is a students' personal creation and is based on preexisting activities, experiences and thoughts $[22,23,24,25]$. The sociocultural constructivist process includes the building of knowledge, through social and cultural interaction among themselves or their social environment. This approach encourages students to face an experiential problem and to resolve them, through collaboration, argumentation and debate. The epistemology of sociocultural constructivism has emerged as a prominent approach to the teaching of science in secondary and higher education [26, 27, 28, 29, 30].

This paper explores the use of a social computing and specifically a social bookmarking site, in geographical and environmental research project of Greek high school students' sample. According to Prichard [31] the social bookmarking use increases students' interaction and leads them to find more interesting the scientific inquires. They can bookmark a paper, add tags, make comments on the content or click on a "like" button if they find the content interesting for their exploration and generally they "are involved in organizing online content and they can collaborate and/or socialize online". Also, Prichard [31] noted that the use of these tools could greatly aid collaborative learning projects both in high and higher education. Thus, in our study, we designed a transdisciplinary research (TdR) project which is characterized by a process of collaboration between students and it is enriched with values, interests and interrelations of them, on a specific real-world problem. Recent research efforts suggest that, the TdR approach is a hybrid combination of mutual learning, building of decision making capacity and social interaction between participants and promotes new ways of research action different from multi- or interdisciplinary approach and applied science. [26, 32, 33]. Specifically, Walter et al. [34] noted that "Because of its ability to handle multi-actor, complex problems, TdR is used extensively in the thematic field of sustainable development. It is therefore an important research type of sustainability science...TdR projects require a specific epistemology, as well as a suitable methodology and organization originating from a socio-cultural constructivist point of view". Thereafter, we implemented this project and then inquired whether the students interacted with each other during the project in the proposed social web tool, based on sociocultural constructivist strategies. Worth noting that the main purpose of this research is to study whether these interactions of students affected their cognitive development and their geographical and environmental approach to the research issue. Based on this purpose, we analyzed the learning process through quantitative content analysis (QCA) and social network analysis (SNA), discussed the research findings, and also we proposed some directions for further research.

\section{METHODOLOGY}

Our research process is guided by the following question: Does the sociocultural constructivist interaction of students in the social Web 2.0 affect their cognitive development and their geographical and environmental approach to the research issue?". Based on this question, we designed a case study TdR project that enabled students to explore a geographical and environmental issue, using a social bookmarking site, in the frame of socialcultural constructivist pedagogy and active- collaborative learning. The focus participants of the project were 16 Greek high school students (aged 15 - 16). They also varied in their socioeconomic and cognitive background. Before the program, most students had a previous experience in geographical and environmental actions, while half had used social computing for educational and research purposes. The project lasted 29 weeks (from October 2011 to May 2012), 3h per week in computer lab. The sample worked in groups of four, and each group had two PC to use.

This project was realized based on the six phases functional-dynamic model of participation as defined by Scholz et al. [32]: (i) definition of a guiding question; (ii) faceting the case; (iii) system representation by a system model; (iv) creating scenarios; (v) conducting a Multi-Attribute Utility Analysis based on both scientific arguments as well as individual stakeholder preferences; and (vi) developing robust orientations for future development. At first, the researcher, who had the role of coordinator and consultant, presented to the students the applications and extensions of a free social bookmarking site, Diigo. Students' interaction in Diigo platform started with the individual introduction of themselves and their participation in research group. Then, the researcher gave the students a questionnaire to fill out their socioethnographic data and a list of geographical and environmental issues. Students chose a geographical and environmental issue "Nuclear Energy", raised the question that "How does nuclear energy affect on society, environment and health?" and created the following groups: nuclear energy, nuclear reactors and security measures; effects on society; effects on the environment; and health effects, A, B, C and D, respectively. In the second work phase of the project, the researcher gave the student groups selected and tested bookmarks and annotations webpage, which contains information and resources for the needs of project, thus cutting the risks of uncontrolled search. Later, however, the working 
groups used the applications of Diigo platform, conducted their own searches on this issue and added their own bookmarks, digital highlights, interactive sticky notes, images and documents under the researcher' supervision. In the middle of the project, the researcher encouraged the students to use a combination of tools, such as Diigo and Google Earth, in order to enrich their resources with multiple layers of geographical data, useful for their geographical and environmental research. Moving to the next phase, each group discussed and commented on the value, quality and usefulness of proposed bookmarks. These bookmarks were tagged with student-specified labels as well as the researcher and were shared with others working groups (i.e., public bookmark) or private and visible only to the student-creator of the bookmark. In the fifth phase, each group evaluated the research work of other groups and together decided on the final form, creating a network of useful online resources or else a new learning community about "Nuclear Energy". Toward the end of the project, the researcher and student groups discussed all exploratory process and suggested ways of using and notification to the wider community. The final goal of the working groups was to create a learning community about a geographical and environmental issue, proceeding from search, processing, evaluating and organizing information to higher levels of learning, such as interactions among themselves, co-construction of new knowledge, developing the capacity to distinguish relations, formulation of generalization and use of mapping, comparison and exploration.

To better understand these community activities, we conducted the QCA and SNA, using the community learning exchanges through shared bookmarks, tags, annotations, interactive sticky notes, digital highlights, images and documents. Cerratto and Rodriguez [35] note that "exchanges are defined as equivalent to a turn taking unit. An exchange consists of at least two utterances; called initiative and response. An evaluative utterance can appear as a third component in a turn". Making reference to Kerbrat-Orecchioni, they also note on the forms of produced exchanges "In the coding, the production of exchanges with two utterances is regarded as minimal exchange and is interpreted as indicating minimal engagement in the conversation. A more significant production, with three utterances, is regarded as a complete exchange and is interpreted as an indication of engagement in the activity". Thus, focusing on the students' cognitive development and their geographical and environmental approach to the research issue, we compared the amount and form (minimal or complete) of the learning exchanges (independently of the type of exchanges) of the working groups in Diigo platform through QCA. In this study content analysis, it was applied the coding scheme (or interaction analysis model) developed by Gunawardena, Lowe and Anderson [36]. This scheme consists of five phases, reflecting the auditing process of co-construction of knowledge by collaborative learning working groups in social web era: (a) Sharing/ Comparing Knowledge, (b) Dissonance (discover/ explore disagreements), (c) Negotiation/ Coconstruction (Synthesis via negotiating meaning), (d) Testing Tentative Constructions, (testing/ modifying proposed synthesis vs. schemas, theory, facts, and beliefs) and (e) Statement/ Application of Newly-Constructed Knowledge (proofs of reaching agreements or meta-cognitive admitting change of knowledge.). According to Lockyer and Patterson [6] "This model suggests successive stages of increasingly higher mental functions. The model can be, and is most often, used to analyze the discourse and social interaction that occurs among learners in an online environment". Thus, we followed Gunawardena's [36] approach to code the learning exchanges had been developed during the project. Then, based on our main purpose, we enhanced this model with other indicators, and specifically with five students' skills, which according to the National Geography Standards [37] guide a geographical and environmental research project: (a) asking geographic questions about spatial distributions and processes (students begin by asking where, what, why, and so what?), (b) acquiring geographic information about distribution (students should learn to use a variety of tools and sources to gather geographic data), (c) organizing geographic information (students should learn a variety of methods for systematically organizing and presenting geographic data), (d) analyzing geographic data (students should be able to identify, understand, explain, and analyze information presented in maps, tables, charts, and graphs), and (e) answering geographic questions (students should be able to: present geographic information in oral and written reports and on maps; make generalizations and apply these generalizations in order to solve real-world problems; and use geographic information to assess the feasibility of proposed solutions). It is noted that according to Brown and LeVasseur [37] "The geographic perspective is an interdisciplinary one that allows us to examine complex issues, including those arising from the interaction of people and their environment, using all available information in order to avoid making short-sighted decisions", a difficult role because of the many ways interaction of a human with the environment. Moreover, they noted that using the spatial and ecological perspective, geography offers a unique way to understand the ever changing relationship of human with environment, to make predictions and to propose solutions for the real-world problems.

As already mentioned, in this study, the SNA is used to analyze the social structure of the learning community in Diigo platform, during the project. The way of students participated and interacted between them provided information about the activities of the learning community. At first, we calculated the indegree and outdegree centrality measures to find the central participants within the network. Based on De Laat [38] "Indegree centrality is a form of degree centrality that counts only those relations with a focal individual reported by other group members and is therefore not based on self reports as is outdegree centrality". Thus, in 
this analysis, the indegree measures provided information about the amount of students that read the shared bookmarks, documents, tags or the sticky notes and comments on bookmarks from a certain student. The outdegree analysis provided information about the amount of shared bookmarks, tags, annotations, interactive sticky notes, digital highlights, images and documents that a student had shared to other members. Then, we conducted a density and multi dimensional scaling (MDS) analysis to describe and visualize the students' interactions, respectively [39]. According to Scott [39] "One of the most widely used, and perhaps over-used, concepts in graph theory is that of 'density', which describes the general level of link age among the points in a graph. A 'complete' graph is one in which all the points are adjacent to one another: each point is connected directly to every other point. Such completion is very rare, even in very small networks, and the concept of density is an attempt to summarize the overall distribution of lines in order to measure how far from this state of completion the graph is. The more points that are connected to one another, the more dense will the graph be" and De Laat [38] making reference to Scott [39] notes the difference between density and centralization "density describes the general level of cohesion in a graph and centralization describes the extent to which this cohesion is organized around particular focal points". Also, as regards the MDS analysis, Scott [39] reported that "The second innovation was the development of multidimensional scaling, a 'scaling' technique for translating relationships into social 'distances' and for mapping them in a social space. Very much in the tradition of Lewin's work on field theory, these developments proved extremely powerful methods of analysis". Thus, in our case, the more students interacted with each other the closer they were on the MDS map [39].

In closing this part of paper, for conducting the analysis of our social network was used the Cyram NetMiner 4.0 program. This program, developed in Korea, is a network analysis software package which helps to perform data transform, network analysis, statistical analysis, and also network visualization. In particular, NetMiner can perform an exploratory analysis with its data analysis and visualization functions $[40,5]$.

\section{RESULTS}

The 312 learning exchanges could be coded with the enhanced scheme of Gunawardena et al. [37] to analyze the socialcultural construction of knowledge. The results of these exchanges are shown in Table 1.

Table 1. Coding the Knowledge Socialcultural Construction Process

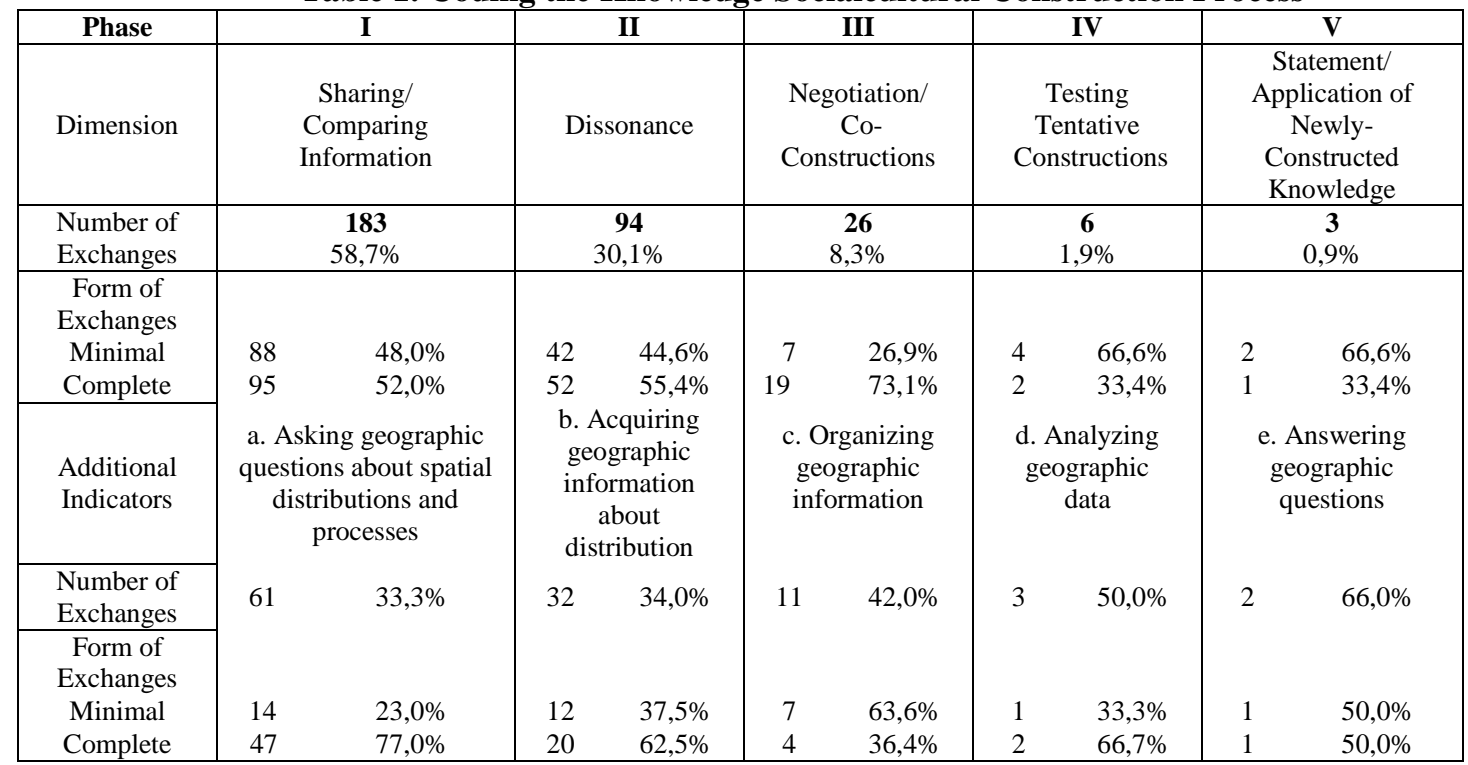

The analysis demonstrates that the sample reached the higher phase of sociocultural constructivist interaction, progressively developing essential skills for an organized and integrated geographical and environmental approach to the research issue, producing a large proportion of complete exchanges. Participants seemed to more critically ask and answer questions to clarify details of statements, negotiate meaning of terms and to make some metacognitive statements, illustrating their understanding that their knowledge or ways of thinking (cognitive schema) have changed as a result of their interaction [37]. Specifically, most of the participants' interaction $(58,7 \%)$ remained in the phase of sharing, or comparing information (Phase I, promoting the first skill, 33,3\% of exchanges in this phase). This is expected because of the research subject. The issues of energy, environment and geography are significant and directly affect our lives. Initially, the sample asked questions, such as what is being examined or investigated and searched, compared and shared relevant information on "Nuclear energy and the effects. However the different views of members on the 
reappearance of "nuclear solution" because of the direct addressing climate change and high energy demands led to the discovery and exploration of dissonance, the exchange of arguments and the further exploration and promotion of other members views, including locating and collecting data, reading and interpreting maps and other graphic representations of spaces and places, organizing and presenting geographic data with photographs, videos, satellite images, diagrams and tables. $30,1 \%$ of the exchanges are of Phase II and 8,3\% of Phase III, promoting the second and third skill (34,0\% and $42,0 \%$ of exchanges in Phases II and III, respectively). Also, some members focused on the recent Great East Japan Earthquake and its resulting tsunamis and the accident at Fukushima Daiichi Nuclear Power Station (NPS) of Tokyo Electric Power Company (TEPCO), developing conclusions based on collected, organized and analyzed data and using geographic information to assess the feasibility of proposed solutions in oral and written reports and on maps. These members reached the two last phases of sociocultural constructivist interaction, producing a small proportion of exchanges $(1,9 \%$ of the exchanges are of Phase II and $0,9 \%$ of Phase III) and promoting the forth and fifth skill (50,0\% and 66,0\% of exchanges in these phases, respectively).

Thereafter, to find the central and noncentral participants we calculated centrality values for each member by using Freeman's degree. There were differences in members' outdegree and indegree values, as Table 2 shows. Members' outdegrees varied between 5 and $13(\mathrm{M}=8.25, \mathrm{SD}=4,352)$ exchanges, and indegrees between 2 and 15 exchanges $(\mathrm{M}=8.25, \mathrm{SD}=2,278)$. Three members, St03, St06, and St13 had the highest outdegrees $(13,11,11$, respectively), and three members, St10, St15, and St16 had very low outdegrees 5, 6, 5, respectively). High outdegree indicates that a member creates connections to the other members of the network and activates other members, regardless of the group. Five members, St03, St06, St09, St11 and St13 had high indegrees $(15,15,15,15,11$, respectively), and five members St07, St08, S10, St15 and St16 had low indegrees $(5,5,2,5,3$, respectively). High indegree indicates prestige or interest towards a member (or his exchanges). Thus, members who are having a high degree (indegree and outdegree summed) have the most connections to others, creating a dynamic research group and enhancing the exploratory process [38].

Table 2. Engagement of members in the network

\begin{tabular}{|c|c|c|c|}
\hline Members & $\begin{array}{c}\text { Total } \\
\text { exchanges }\end{array}$ & $\begin{array}{l}\text { Outdegree } \\
\mathrm{M}=8,25 \\
\mathrm{SD}=4,352\end{array}$ & $\begin{array}{l}\text { Indegree } \\
\mathrm{M}=8,25 \\
\mathrm{SD}=2,278\end{array}$ \\
\hline St01 & 15 & 7 & 7 \\
\hline $\begin{array}{l}\text { St02 } \\
\end{array}$ & 13 & 7 & 8 \\
\hline St03 & 28 & 13 & 15 \\
\hline St04 & 14 & 7 & 7 \\
\hline St05 & 24 & 9 & 7 \\
\hline St06 & 36 & 11 & 15 \\
\hline St07 & 21 & 8 & 5 \\
\hline St08 & 23 & 7 & 5 \\
\hline St09 & 26 & 11 & 15 \\
\hline St10 & 15 & 5 & 2 \\
\hline St11 & 28 & 10 & 15 \\
\hline St12 & 14 & 7 & 6 \\
\hline St13 & 29 & 11 & 11 \\
\hline St14 & 9 & 8 & 6 \\
\hline St15 & 8 & 6 & 5 \\
\hline St16 & 9 & 5 & 3 \\
\hline Total & 312 & 132 & 132 \\
\hline
\end{tabular}

Further, a MDS (Fig. 1) was calculated to visualize the patterns of members' interaction among themselves. The goodness of fit for MDS is the stress value, which indicates quality of the MDS map (a stress value below $10 \%$ is regarded as adequate fit). In our analysis, the stress value was satisfactory $(0.134)$. 


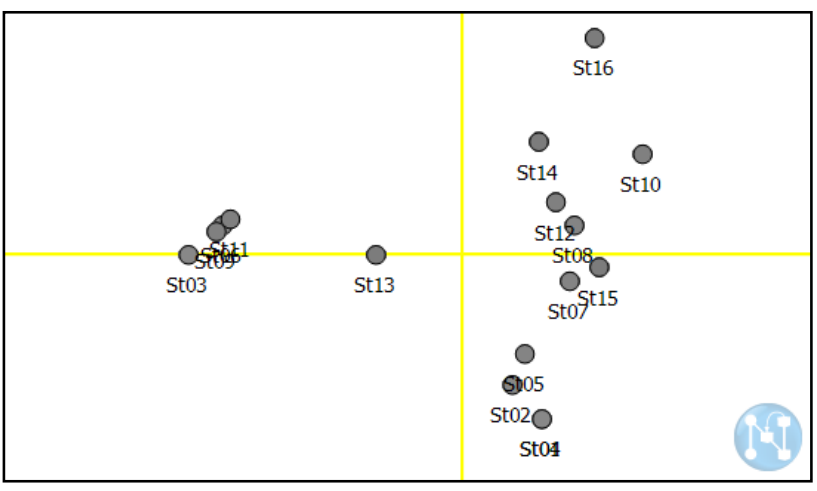

Figure 1. Interaction pattern within the network

In general we can say that all members interacted with each other and most of them had strong links, but to get an indication of the overall linkage of members in the network we examined the density of interaction among members (the average number of links between members and the value varies between 0 and 1)[38]. In our case, the density of interaction was 0.55 , which tells us that $55 \%$ of members collaborated through Diigo during the research project which was which was encouraging and positive.

\section{DISCUSSION OF RESEARCH FINDINGS}

This study indicates that the sociocultural constructivist interaction of students in Diigo affected their cognitive development and their geographical and environmental approach to the research issue, producing a large proportion of complete exchanges. The results have shown that the density value of members' interaction was at a satisfactory level, and particularly all members participated in the project and some of them enhanced the research process, activating the other members, regardless of the group. The maintenance of consistent groups and the interaction among members of different groups, with mostly complete exchanges, throughout the project showed the conscious selection of the sample to interact and construct new knowledge, creating an active social network (with remarkable distinction in the cohesion, power and role structures). With the use of Diigo applications, the students seemed to follow an auditing process of search, comparison and sharing relevant information, exchange of arguments, further exploration and promotion of other views, and also assessment the feasibility of proposed solutions, reading and interpreting maps and other graphic representations of spaces and places. All these actions led participants to reach the higher phase of sociocultural constructivist interaction, progressively developing essential geographic skills.

Overall we can conclude that the proposed use of social networks in secondary education to enhance geographical and environmental skills of students had positive learning outcomes. However, according to Lockyer and Patterson [6] "It may be considered that integrating the use of open Web 2.0 social networking sites into the formal education setting brings with it a need to explore this further. Research in this area should investigate the professional relationship and expectation implications for teachers and students when they begin to interact in open social networking sites for educational purposes". For further research, we need to examine study suggestions and parameters, such as: (a) correlation between central and noncentral participants' demographic variables with their geographical and environmental approaches and the degree of interaction among themselves in exploratory process, (b) the teachers' role in this research process and the training in the use of digital technologies, (c) the recognition of the limitations, and also (d) the need to continue to explore the issue with other sample of high school students from various places in Greece.

\section{REFERENCES}

[1] T. O'reilly, What is Web 2.0: Design patterns and business models for the next generation of software, Communications \& strategies, (1), 2007, 17.

[2] M. F. Goodchild, In the World of Web 2.0, International Journal, (2), 2007, 24-32.

[3] M. Greaves and P. Mika, Semantic Web and Web 2.0. Web Semantics:Science, Services and Agents on the World Wide Web,6, 2008, 1-3.

[4] S. Yim, and M. Shin, Effects of the Web 2.0 and Social Network Services Environment on Information Quality and Intentions to Re-Use, 2013, URL: http://www.pacis-et.org/file/2013/PACIS2013-065.pdf

[5] R. Aviv, Z. Erlich, G. Ravid, and A. Geva, Network analysis of knowledge construction in asynchronous learning Networks, Journal of Asynchronous Learning Networks, 7(3), 2003, 1-23.

[6] L. Lockyer, and J. Patterson, Integrating social networking technologies in education: a case study of a formal learning environment, In Advanced Learning Technologies, Proc. 9th IEEE Conf. ICALT'08, 2008, 529-533.

[7] P. N. Chou and H. H. Chen, Engagement in online collaborative learning: A case study using a Web 2.0 tool, Journal of Online Learning and Teaching, 4(4), 2008, 574-582.

[8] S. Dawson, A study of the relationship between student social networks and sense of community, Educational Technology \& Society, 11(3), 2008, 224-238. 
[9] E. Klopfer, S. Osterweil, J. Groff, and J. Haas, Using the technology of today in the classroom today: The instructional power of digital games, social networking, and simulations and how teachers can leverage them. The Education Arcade, 2009, URL:http://education.mit.edu/papers/GamesSimsSocNets_EdArcade.pdf

[10] E. Romero-Frías, and J. L. Arquero Montaño, Exploring the use of Social Network Sites on accounting education: A social constructivist approach, URL: http://personal.us.es/arquero/jornada/docs/25.pdf

[11] W. Y. S. Chou, Y. M. Hunt, E. B. Beckjord, R. P. Moser, and B. W. Hesse, Social media use in the United States: implications for health communication, Journal of medical Internet research, 11(4), 2009.

[12] E. Estellés, E. del Moral, and F. González, SBS as Facilitators of Learning and Research Collaborative Processes: The Diigo Case, IJELLO, 6 (1), 2010, 175-193.

[13] S. Bennett, A. Bishop, B. Dalgarno, J. Waycott, and G. Kennedy, Implementing Web 2.0 technologies in higher education: A collective case study, Computers \& Education, 59(2), 2012, 524-534.

[14] C. Greenhow, B. Robelia, and J. E. Hughes, Learning, Teaching, and Scholarship in a Digital Age Web 2.0 and Classroom Research: What Path Should We Take Now?, Educational Researcher, 38(4), 2009, 246-259.

[15] E. Exarchou, and Aik. Klonari, A pre-study on the Use of Web 2.0 Social Networking Technologies in Geographical and Environmental Learning for Sustainability of Greek Secondary Students, Proc. 13th International Conf. on Environmental Science and Technology (CEST), Greece, 2013256

[16] E. Exarchou, and Aik. Klonari, Using a Social Bookmarking Systems to enhance the Environmental and Geographical Learning of secondary students. A pre- study review, Proc. Conf. on Constructionism 2012, Theory, practice and impact, Greece, $2012,671$.

[17] C. Redecker, K. Ala-Mutka, M. Bacigalupo, A. Ferrari, and Y. Punie, Learning 2.0: The impact of Web 2.0 innovations on education and training in Europe. Final Report, European Commission- Joint Research Center- Institute for Prospective Technological Studies, Seville, 2009, URL: ftp://ftp.jrc.es/pub/EURdoc/EURdoc/JRC55629.pdf

[18] K. R. Parker, and J. T. Chao, Wiki as a teaching Tool, Interdisciplinary Journal of Knowledge and Learning Objects, 3, 2007, 5772.

[19] Y. Woo, and T.C. Reeves, Meaningful interaction in web-based learning: A social constructivist interpretation, The Internet and Higher Education, 10(1), 2007, 15-25.

[20] H. Kanuka, and T. Anderson, Online social interchange, discord and knowledge construction. Journal of Distance Education, 13(1), 1998, 57-75.

[21] M. Stauffacher, A. I. Walter, D. J., Lang, A. Wiek, and R. W. Scholz, Learning to research environmental problems from a functional sociocultural constructivism perspective: the transdisciplinary case study approach, International Journal of Sustainability in Higher Education, 7(3), 2006, 252-275.

[22] L. Vygotsky, Mind in Society (London: Harvard University Press, 1978).

[23] M. Lucas, C. Gunawardena, and A. Moreira, Assessing social construction of knowledge online: A critique of the interaction analysis model. Computers in Human Behavior, 30, 2014, 574-582.

[24] E. von Glasersfeld, Radical constructivism: A way of knowing and learning (London: Falmer,1995).

[25] T. Scott, M. Cole, and M. Engel, Computers and education: A cultural constructivist perspective, Review of Research in Education, $18,1992,191-251$.

[26] C. Kynigos, Niches for Constructionism: forging connections for practice and theory, Proc. Conf. on Constructionism 2012, Theory, practice and impact, Greece, 2012, 40-51.

[27] E. Klein, and E. Merritt, Environmental Education as a Model for Constructivist Teaching, The Journal of Environmental Education, 25 (3), 1994, 14-21.

[28] C. McRobbiea, and K. Tobin, A social constructivist perspective on learning environments, International Journal of Science Education, 19 (2), 1997, 193 - 208.

[29] D. Jonassen, K. Peck, and B. Wilson, Learning with technology: A constructivist perspective. (Eds.), Special Education Technology, 16, Prentice Hall, 1999.

[30] T. Risse, Social Constructivism and European Integration, Antje WIENER (ed), Thomas (ed), European Integration Theory, 2004, 159-176.

[31] C. Prichard, Using social bookmark sites for independent reading projects, The JALT CALL Journal, 6(2), 2010, 115-128.

[32] R. W. Scholz, D. J. Lang, A. Wiek, A. I. Walter, and M.Stauffacher, Transdisciplinary case studies as a means of sustainability learning: historical framework and theory, International Journal of Sustainability in Higher Education, 7(3), 2006, 226-251

[33] M. Stauffacher, Beyond neocorporatism? Transdisciplinary case studies as a means for collaborative learning in sustainable development. In: Gross M., Heinrichs H., (eds) Environmental Sociology. European perspectives and interdisciplinary challenges. Springer, Dordrecht, the Netherlands, 2010, 201-216.

[34] A. I. Walter, S. Helgenberger, A. Wiek, and RW. Scholz, Measuring societal effects of transdisciplinary research projects: design and application of an evaluation method, Evaluation and Program Planning, 30(4), 2007, 325-338.

[35] T. Cerratto, and H. Rodriguez, Studies of Computer Supported Collaborative Writing. Implications for System Design. In COOP, 2002, 139-154

[36] C. N. Gunawardena, C. A. Lowe, and T. Anderson, Analysis of a global online debate and the development of an interaction analysis model for examining social construction of knowledge in computer conferencing, Journal of Educational Computing Research, 17(4), 1997, 395-429.

[37] B. J. Brown, and M. L. Le Vasseur, Geographic Perspective. Perspectives of global education: A sourcebook for classroom teachers, 1981, 33-39.

[38] M. De Laat, Network and content analysis in an online community discourse, Proc. Conf. on Computer Support for Collaborative Learning: Foundations for a CSCL Community. International Society of the Learning Sciences, NJ, 2002, 625-626.

[39] J. Scott, Social Network Analysis: A handbook (London: SAGE Publications, 1991).

[40] Netminer, URL: http://www.netminer.com/images/NetMiner4_E.pdf 